\title{
Antioxidant properties of aqueous media with molecular hydrogen used in tnviromental medicine
}

\author{
(C) Anatoly A. Lapin, ${ }^{1}{ }^{*}{ }^{+}$Irek G. Garifullin, ${ }^{2}$ Valery N. Zelenkov, ${ }^{3}$ and Sergey D. Filippov ${ }^{4}$ \\ ${ }^{1}$ Kazan State Power Engineering University. Krasnoselskaya St., 51. Kazan, 420066. Republic of Tatarstan. \\ Russia. Phone: +7 (843) 519-42-67.E-mail: lapinanatol@mail.ru \\ ${ }^{2}$ NLLC "Clinic of green medicine". Galimzhan Barudi St., 4, room 2039. Kazan, 420032. \\ Republic of Tatarstan.Russia.Phone:+7 (917)284-47-77.E-mail: ireknl@mail.ru \\ ${ }^{3}$ All-Russian Scientific Research Institute of Vegetable Growing - Branch of the FSBSI Federal Scientific \\ Vegetable Center. Vereya Village, 500. Ramenskoye District. Moscow Region, 140186. Russia. \\ E-mail: zelenkov-raen@mail.ru \\ ${ }^{4}$ LLC “AKVALON”, st. Ordzhonikidze, 41-33, Chelyabinsk. 454091. Russia. \\ Phone:+7950-725-7831.E-mail:2665654@mail.ru
}

\begin{abstract}
*Supervising author; ${ }^{+}$Corresponding author
Keywords: antioxidant activity, total antioxidant activity, coulometric analysis method, hydrogen, water, activation, redox potential, urine, oral fluid.
\end{abstract}

\section{Abstract}

The article presents the results of the biotechnological study of aquatic environments with molecular hydrogen by antioxidant activity. Molecular hydrogen has selective antioxidant activity against dangerous free radicals. It has anti-inflammatory, anti-apoptotic, anti-allergic effects and stimulates energy metabolism. The problem is urgent nowadays because of the great interest to molecular hydrogen as an antioxidant over the past ten years, but its quantitative metabolic parameters have not been estimated yet. The total antioxidant activity of aquatic systems saturated by hydrogen have been studied using coulometric analysis. It was shown that their antioxidant activity of aquatic systems increase of 8-10 times depending on the operating conditions and time of the "H2 Inhaler" device and 3 times when using a mineral generator active Hydrogen "Aquaspectr Mineral". The effect of molecular hydrogen have been studied by changing the antioxidant status of the human body, which was determined by changing the total antioxidant activity of urine and oral fluid during inhalation of hydrogen and oral administration of hydrogen-saturated water. The synergistic effects has been revealed in determining the total antioxidant activity of the oral fluid in the range from 14.02 to $17.59 \%$ rel. and synergism/antagonism of urine in the range from 37.17 to $27.62 \%$ rel., compared with control measurements. The total antioxidant activity was determined using electro-generated bromine, the samples were analyzed on an Expert-006 coulometer (Econix-Expert LLC, Russia) according to our certified method.

\section{References}

[1] S.V. Chepur, N.P. Pluzhnikov, O.G. Khurtsilava et al. Biological effects of molecular hydrogen and the possibility of its use in clinical practice. Successes of modern biology. 2017. Vol.137. No.3. P.311-318. (russian)

[2] N.A. Aristova, N.A. Berkutov, I.M. Piskarev. Storage of water with negative redox potential. Water: chemistry and ecology. 2012. No.7. P.81-83. (russian)

[3] A.A. Lapin, Yu.V. Chugunov, and S.D. Filippov. The total antioxidant activity of the aqueous systems, saturated with hydrogen. Butlerov Communications. 2015. Vol.44. No.12. P.61-66. DOI: 10.37952/ROI-jbc01/15-44-12-61

[4] A.A. Lapin, A.A. Kalayda, S.D. Filippov and V.N. Zelenkov. Biochemical effects of molecular hydrogen in aqueous systems. International Water and Energy - 2018: a collection of reports in 2 volumes T. I. Kazan: Kazan. state energy Univ. 2018. Vol.1. 337p. P.81-84. (russian)

[5] N.A. Aristova, I.M. Piskarev. Water purification in large volumes due to chain reactions initiated by hydroxyl radicals. Modern high technology. 2008. No.2. P.42-46. (russian)

[6] S.N. Lebedeva, S.D. Zhamsaranova, S.A. Chukaev, L.D. Dymsheeva. Evaluation of the diet and antioxidant activity of biological fluids of students. Nutrition issues. 2018. Vol.87. No.1. P.35-43. DOI: 10.24411/0042-8833-2018-10004. 
ANTIOXIDANT PROPERTIES OF AQUEOUS MEDIA WITH MOLECULAR HYDROGEN USED ...

$140-146$

[7] M. Ichihara, S. Sobue, M. Ito et al. Beneficial biological effects and the underlying mechanisms of molecular hydrogen - comprehensive review of 321 original articles. Med. Gas Res. 2015. Vol.5. P.12.

[8] A.A. Lapin, S.D. Litvinov, I.I. Idrisova, V.N. Zelenkov. Biochemical examination of urine with the use of the material "Litar" in terms of total antioxidant activity. Bulletin of the Medical Institute "REAVIZ": rehabilitation, doctor and health. 2019. No.3(39). P.154-165. (russian)

[9] A.A. Lapin, and V.N. Zelenkov. Antioxidant properties of water-soluble pectins of amaranth leaves. Butlerov Communications. 2010. Vol.20. No.4. P.79-85. ROI: jbc-02/10-20-4-79 